Article

\title{
New High Voltage Interconnections with Islands in the Mediterranean Sea: Malta and Sicily. Analysis of the Effects on Renewable Energy Sources Integration and Benefits for the Electricity Market
}

\author{
Mariano Giuseppe Ippolito ${ }^{1}$, Salvatore Favuzza ${ }^{1}$ (i) , Fabio Massaro ${ }^{1, *}$ (i) , Liliana Mineo ${ }^{1}$ and \\ Calogero Cassaro ${ }^{2}$ \\ 1 Department of Energy, Information Engineering and Mathematical Models, DEIM, University of Palermo, \\ Viale delle Scienze, Building n.9, 90128 Palermo (Pa), Italy; marianogiuseppe.ippolito@unipa.it (M.G.I.); \\ salvatore.favuzza@unipa.it (S.F.); liliana.mineo@unipa.it (L.M.) \\ 2 Terna Rete Italia S.p.A., Direzione Territoriale Centro Sud, Via Castellana, 195-90135 Palermo, Italia; \\ calogero.cassaro@terna.it \\ * Correspondence: Fabio.massaro@unipa.it; Tel.: +39-(0)91-2386-0295
}

Received: 14 March 2018; Accepted: 29 March 2018; Published: 4 April 2018

\begin{abstract}
The present paper shows the benefits coming from the operation of the recent electrical high voltage (HV) interconnections between Sicily, Malta and mainland Italy. These new interconnections allow zonal prices of electricity considerably lower than in the past, ensuring greater flexibility to the system and a better integration of Renewable Energy Sources (RES). After briefly illustrating the two high-voltage electrical systems (Sicily and Malta), and having provided a description of the interconnection cable with Malta and its protection devices, the authors hypothesized two modes of operation (Sicily-Malta system islanded or interconnected to the rest of Europe). For the first case (islanded) some simulations are performed through the use of an electric network model realized in the Neplan ${ }^{\circledR}$ environment, and for the second case an analysis of one year real data was made. The results of the simulation, thanks to the use of a power flow tracing method, show that this new interconnection between the two islands (Sicily and Malta) allows an important improvement in the integration and dispatching of the power generated by RES of the Sicilian territory, better operation of traditional Sicilian generation units, lower electricity zonal prices and a significant reduction in emissions from obsolete fuel oil thermal units located in Malta.
\end{abstract}

Keywords: Sicily-Malta interconnection line; Sicily-Italy doubling connection; Renewable Energy Sources (RES) integration; power tracing technique

\section{Introduction}

In the last fifteen years, traditional power generation units (mostly Combined Cycle Gas Turbine (CCGT)) located in the Sicilian territory have produced less energy than suggested by the optimal operating point. This situation has arisen due to the significant increase in generation from renewable energy sources, both wind farms directly connected to the high voltage transmission system (HV) and photovoltaic plants connected to the medium voltage (MV) infrastructure. Furthermore, the electricity demand suffered a slight decrease due to the economic crisis that has been recorded in the last period [1].

The increase in generation from Renewable Energy Sources (RES), both in Sicily and in the North African countries, with particular reference to the photovoltaic source, opens up a very interesting scenario for the planning of new interconnection links between the electrical systems [2]. 
In the last few years worldwide there has been a growing interest in high voltage cable connections both AC and DC over long submarine distances, as reported in [3-6].

The new high voltage submarine cable (High Voltage Alternating Current (HVAC)) submarine cable between Sicily and the island of Malta is part of this evolution of the electrical grid; this intervention has been the subject of EU funding under the European Energy Recovery Program (EEPR) [7]. The power line was created unilaterally by one of the system operators involved, Enemalta (the main provider of generation and distribution services), which is the owner and operator of the cable. The new power line is part of the trans-European energy network (TEN-E).

The Maltese electrical system is now obsolete; the production of electricity takes place, for the most part, using very polluting traditional generation units. The island of Malta, together with Cyprus, was one of the rare examples of complete insular electrical systems in Europe. As is often the case with isolated systems, the cost of producing electricity (from traditional sources) is very high, the electrical infrastructure is poorly meshed and certainly not very reliable. The new submarine cable, presented later in this paper, aims to significantly improve the reliability of the electrical grid and certainly increase production availability. Moreover, the new connection favors the development and dispatching of renewable sources located in the Sicilian territory.

This new HV connection will allow the Maltese transmission system operator to significantly reduce the generation of electricity from traditional and highly polluting sources currently used. This will reduce electricity costs, emissions into the atmosphere, addressing the EU's climate and energy package together with the 20-20-20 targets [8].

The second important HV new interconnection has been realized between Sicily and the Italian mainland. In this case it is a doubling of a preexisting connection, which will however guarantee greater stability to the Sicilian electricity system, allowing a significant reduction in the price of electricity and making the electricity market much more flexible.

In this paper a brief description is given exclusively of the interconnection cable with the island of Malta since, compared to the Sicily-Italy link, it is certainly more interesting from a technical point of view, being one of the longest connections in the world in alternating current.

\section{Submarine Interconnection between Italy and Malta}

The new electrical interconnection link between the Maltese and the Sicilian islands was built in HVAC at $220 \mathrm{kV}$ and is one of the longest interconnecting high voltage submarine power lines in alternating current in the world. The Sicilian end of the electrical infrastructure consists of a $19 \mathrm{~km}$ long underground cable, starting from the $220 \mathrm{kV}$ electrical station in Ragusa (RG). The underground section of the cable ends at the station of Marina di Ragusa, and here are the joints for the submarine cable, about $98 \mathrm{~km}$ long. The Maltese end of the line belongs to the $220 \mathrm{kV} / 133 \mathrm{kV}$ Maghtab power station.

The new connection consists of a single (three-conductor) circuit with a rating of $200 \mathrm{MW}$. The cable is equipped with a double protection system, consisting of a residual current circuit breaker coupled with a distance protection. In the two terminal stations a compensation system is installed through a three-phase reactor to compensate for the reactive power required by the HVAC line in various working conditions.

As already mentioned, the $220 \mathrm{kV}$ AC power line in alternating current consists of:

- an underground section, about $20 \mathrm{~km}$ long, consisting of three single-core cables;

- a submarine cable section, $98 \mathrm{~km}$ long, consisting of a three-core cable.

The total length of this cable is approximately $118 \mathrm{~km}[9]$.

Due to voltage regulation problems, the connection can be energized only from the Italian station to the Maltese one, to avoid the reactive energy consumption from the cable causing serious voltage violations on the Maltese power grid [9]. 


\section{Cable Protection System}

Terna (Italian TSO), together with Enemalta, designed the protection system described below. As shown in Figure 1, the new $220 \mathrm{kV}$ connection is equipped, in each station (SE Ragusa-SSE Ragusa-SE Maghtab), with a completely redundant monitoring, control and protection system, in order to guarantee adequate safety margins for the operation of the two interconnected electricity networks. Considering the importance of the new connection and its terminal stations, the protection system is able to detect the different types of faults that may occur both on the connection cable and near the electrical stations. More in detail, each of the different types of faults that may affect the interconnection system must be detected by at least two protections, based on different operating principles. A fault on the $220 \mathrm{kV}$ cable, or on the compensating reactors connected to the cable end, must be eliminated in basic time by opening the line switches located at the end of the cable HV (at SSE Ragusa and SE Maghtab). This goal has resulted in a completely duplicated system architecture consisting of two protection systems including a differential line protection (called 87L) with integrated distance protection function (called 21.2) and a line distance protection (called 21.1) with associated telepylotation scheme. To guarantee the intervention priority of one of the two protection systems, automatically transferring (without delay) the command signal to the other in the event of a fault, both protections use the fiber optic connection (FO), laid together with the submarine cable; this connection is used by the first protection to transmit current signals measured in the two terminals from one end to the other, while the second one to send the logic signal used for the telepilotage system. As already indicated, the differential protection of the line is also integrated with the distance protection function, in which the first step is normally inactive and is ready to intervene in basic time in case of anomaly of the line differential protection, mainly due to loss of communication in FO. The zones following the first one, of both distance protection devices, have the reserve function for faults external to the cable line. In addition to the protection systems described above, a further system is provided for the protection of the short overhead connection between the Ragusa SE, owned by Terna, and the SSE Ragusa owned by Enemalta. More specifically, in the station Ragusa (Terna), the line upright dedicated to the Sicily-Malta connection is equipped with two distance protection devices (21.1 and 21.2) that command the opening of the user switch (52U) located in the same station (Figure 1. This protection system, in addition to protecting the short section of the line up to the SSE Ragusa, may also be used for the main line protections of the SSE Ragusa described above. The first step of both distance protections, appropriately delayed, is controlled by a block diagram activated by one of the following signals:

- intervention of the line differential protection (87 L);

- $\quad$ starting in the forward direction of one of the two distance protections of the SSE Ragusa;

- $\quad$ start-up of the shunt reactor protections of the SSE Ragusa.

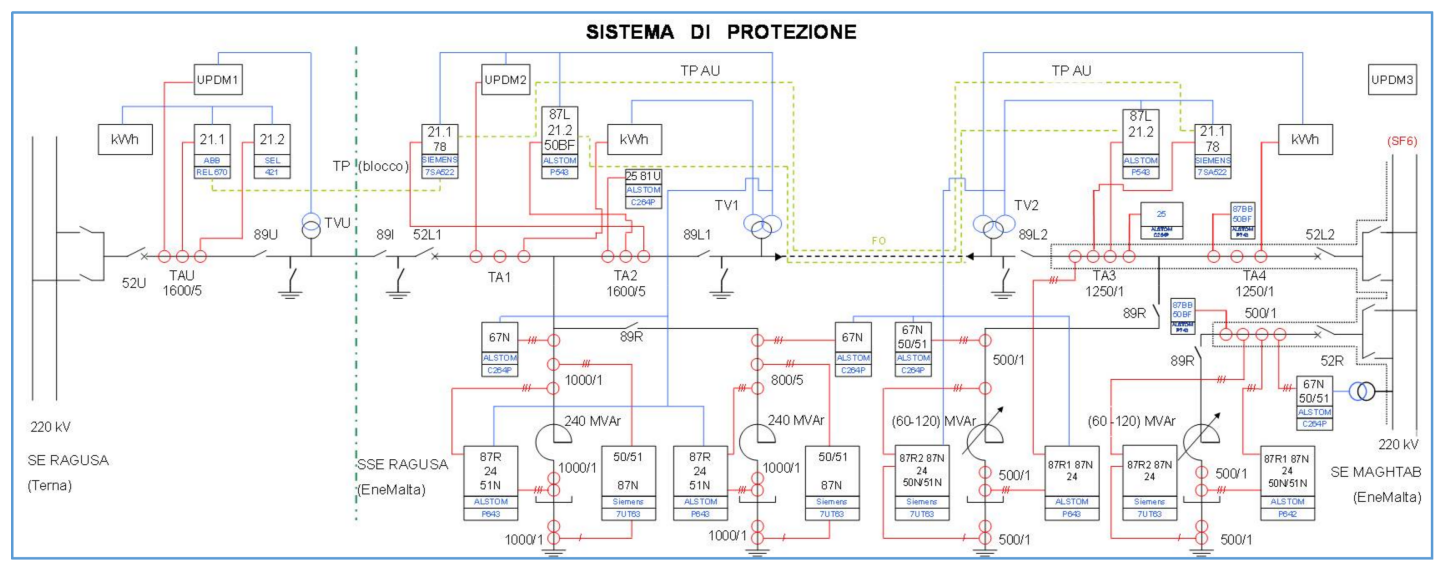

Figure 1. Single line diagram and protection devices of the $220 \mathrm{kV}$ connection Sicily-Malta. 
The next step, however, regulated according to criteria of selectivity, has the function of reserve in case of faults external to the protected overhead section.

To guarantee the correct operation of the $220 \mathrm{kV}$ connection cable, the automatic fast and slow reclosing located in the Ragusa SE, SSE Ragusa and SE Maghtab must be excluded. Furthermore, the closing of the line switches $(52 \mathrm{~L})$ is controlled by a parallel device that controls the voltage difference parameters $(\Delta \mathrm{V} \%)$ and angle difference $(\Delta \Phi)$.

\section{Sicilian and Maltese Transmission System}

The electric transmission system located in Sicily consists of three voltage levels, $400 \mathrm{kV}, 220 \mathrm{kV}$ and $150 \mathrm{kV}$. The $400 \mathrm{kV}$ network consists of a few lines and extends substantially in the eastern part of the island where the connections to the mainland are based. The $220 \mathrm{kV}$ electrical system forms a ring along the Sicilian coast. The rest of the transmission system consists of $150 \mathrm{kV}$ power lines characterized by reduced transport capacity. There are three major and important generation units connected to the transmission network. All of these are traditional and are located at three strategic points on the island. There is also a large pumped hydroelectric unit. In recent years, renewable energy sources (RES) have become widespread throughout Sicily following the incentives proposed by the Government for the development of these sources. So, new and large wind farms have been mainly connected to the $150 \mathrm{kV}$ transmission system. Today the average electricity demand in Sicilia amounts to about $2100 \mathrm{MW}$ [9], the renewable energy production systems connected to the HV network in Sicily would be more than sufficient to satisfy the demand, but for problems related to the reliability of the system, they are often cut off. The Sicilian electric system is connected to mainland Italy through submarine $400 \mathrm{kV}$ connections [2]. A model of Sicilian and Maltese interconnected electricity systems was specifically developed with the NEPLAN ${ }^{\circledR}$ (10.7.4, NEPLAN AG, CH-8700 Küsnacht (ZH), Switzerland) oftware in order to study, through simulations, the various operating conditions and analyze the energy exchange between the systems. The Maltese transmission system consists of an infrastructure with a nominal voltage of $132 \mathrm{kV}$ [10]; it appears to be of modest size and serves to connect substantially the main generation units from traditional sources. Only thermal generation units (quite polluting) are installed, which use fossil resources, and which practically generated all the electrical demands of the Maltese loads. Before the construction of the new submarine cable with the Sicilian electrical grid, the Maltese power grid was completely isolated. Today, however, the connection with Sicily is a very important electrical bridge between the island of Malta and the rest of the European electricity system, which makes the Maltese network considerably more stable and reliable than before. The Enemalta company is both the Maltese electricity system operator and the owner of two thermoelectric power units that cover the electricity needs of Malta and Gozo. As it is known, Malta has no primary energy resources, so the generation of electricity through the use of these power units depends entirely on imported fuels, such as heavy fuel oil and in particular light distillates; all this has important economic repercussions on the price of electricity. The new submarine link with Sicily, in addition to the already mentioned improvements in terms of stability and efficiency of the Maltese electricity system, will significantly reduce the working hours of the production units supplied with fuel oil, with tangible benefits both in terms of environmental problems such as carbon dioxide emissions and the ability to buy cheap electricity from Sicily.

\section{Operating Scenario and Tracing Technique}

This section describes two operating conditions; the first in which Sicily and Malta are connected to each other but islanded from the European network [11], the second in which Siciliy and Malta are connected to Europe (islanded and connected). The first one is simulated on the implemented electrical system model. The numerical evaluations have been carried out through the NEPLAN ${ }^{\circledR}$ software, and have as main objective the demonstration of the relationship between the new network structure and the exploitation of RES in Sicily. The second one analyses one year real operational data. 


\subsection{Islanded Configuration}

The first condition (islanded) is reasonably the worst and is useful to analyze the most critical condition. Thus operating, the two transmission systems (Sicilian and Maltese) work together in sync. Obviously the real situation is much more favorable as it provides for the connection also to the rest of the European system. It is emphasized that the generation of electricity from small photovoltaic plants connected to MV and LV networks, assumed to be equal to $400 \mathrm{MW}$, was deducted from the total energy demand of the two islands; in this way, only the remaining part of the electricity needs will be provided by the thermal and wind units. For the islanded configuration, the authors propose three simulated scenarios that are characterized by the same value of demand for electricity and the same generation by the PV and hydroelectric units. They diversify for the production of electricity from wind sources to the disadvantage of traditional units. In particular, the two main wind farms are connected to the $220 \mathrm{kV}$ grid, near the "Partanna" and "Chiaramonte-Gulfi" electricity stations. Base Scenario is the standard one, without exchange of electricity between the two systems, while the other two scenarios simulate a very high energy production from the wind system and a substantial exchange of electricity to Malta. The calculations of the load flow are performed, starting from these scenarios, to study the operating conditions of the network with particular reference to power flows on the networks to identify the emergence of any overloads in some lines of the electrical systems. Subsequently, the load flow is evaluated for the implementation of a power flow tracing method, which provides important data on the power contribution to the power exported through the new power line [12].

\subsubsection{Base Scenario}

As mentioned, in this scenario the absence of energy exchange on the new submarine link is assumed. The generation of electricity from wind power is rather limited and amounts to $200 \mathrm{MW}$. Table 1 shows the data used for the simulations. Figure 2 shows the power flows on the lines near the Ragusa station.

Table 1. Data used in various scenarios.

\begin{tabular}{lccc}
\hline Data & $\begin{array}{c}\text { Base Scenario } \\
\text { P (MW) }\end{array}$ & $\begin{array}{c}\text { Scenario 1 } \\
\text { P (MW) }\end{array}$ & $\begin{array}{c}\text { Scenario 2 } \\
\text { P (MW) }\end{array}$ \\
\hline Total consumption & 2400 & 2400 & 2400 \\
Total HV grid consumption & 2000 & 2000 & 2000 \\
Total HV grid consumption and pumped storage & 2145 & 2290 & 2290 \\
Pumped storage & 145 & 290 & 290 \\
Thermal plants production & 1865 & 1755 & 1555 \\
Hydroelectric production & 80 & 80 & 80 \\
Wind production on HV grid & 200 & 600 & 800 \\
Photovoltaic production on MV grid & 400 & 400 & 400 \\
Power exchange Sicily-Malta & 0 & 145 & 145 \\
\hline
\end{tabular}

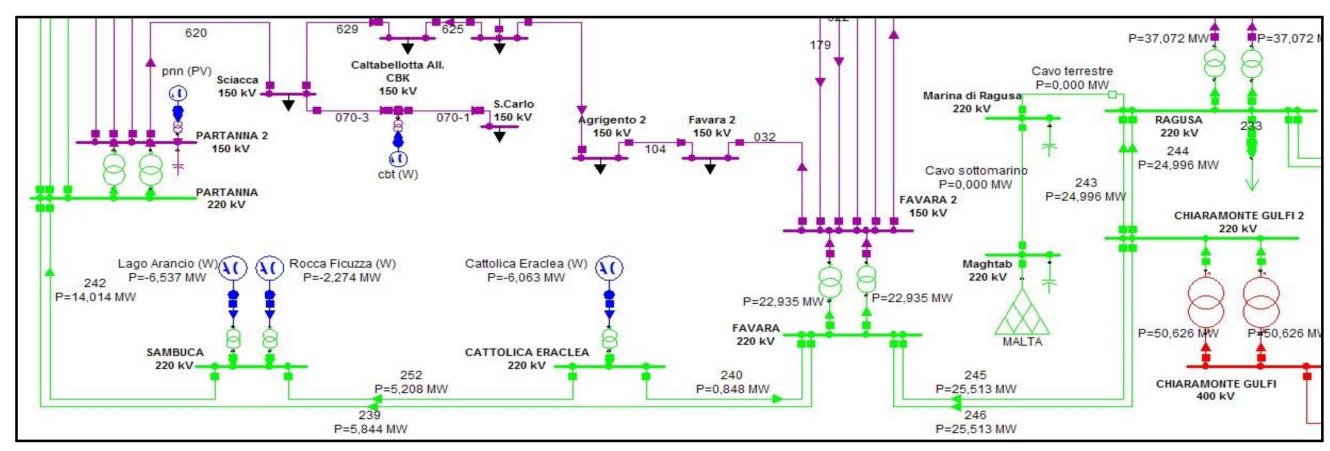

Figure 2. Base Scenario-Power flows on the portion of the network near the submarine interconnection connected to Ragusa station. 


\subsubsection{Scenario 1}

In this scenario, an exchange of electricity between the two systems is assumed and in particular an export from the Sicilian to the Maltese system is taken into consideration. In this case the production of wind farms is increased up to the value of $600 \mathrm{MW}$. As mentioned previously, the power input from the wind farms connected to the "Sambuca" and "Cattolica Eraclea" stations is increased up to $80 \%$ of their nominal power. Table 1 shows the data used to simulate this scenario.

This scenario shows how wind farms contribute to the export of energy to Malta, Figure 3. In fact, this figure shows how the power flows on $220 \mathrm{kV}$ lines are reversed compared to the previous scenario. More particularly, power flows are reversed on the numbered lines 239, 245, 246 and 252, thus transporting energy to the stations of "Favara" and "Chiaramonte Gulfi".

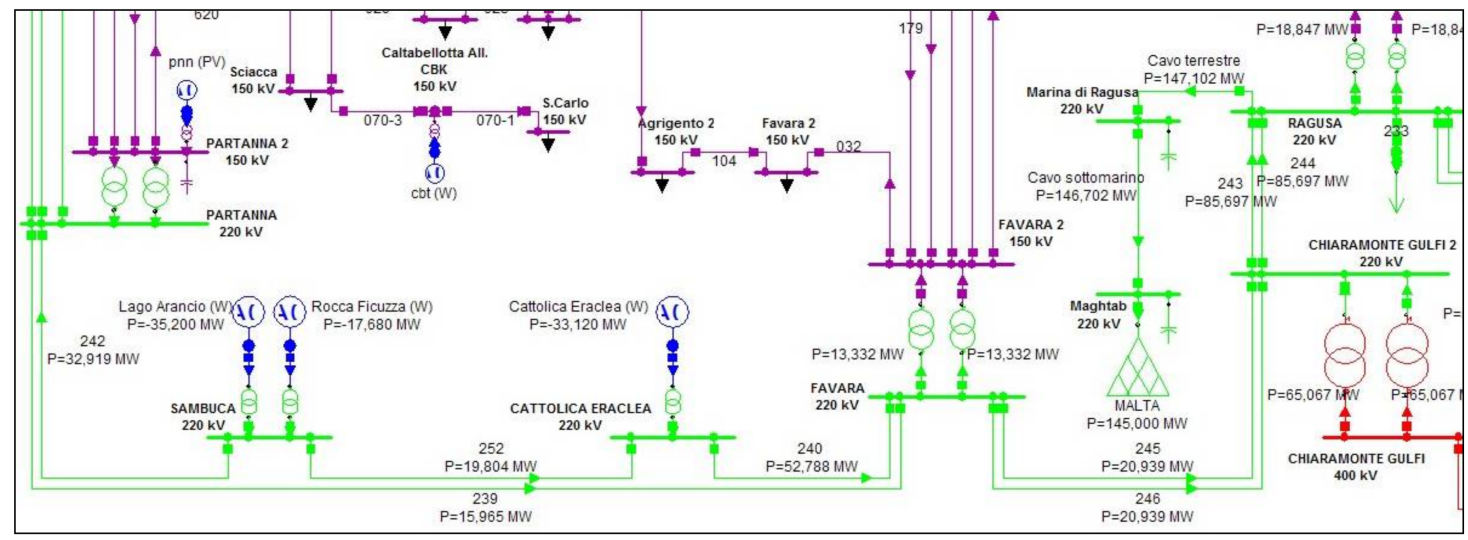

Figure 3. Scenario 1-Power flows on the portion of the network near the submarine interconnection connected to Ragusa station.

\subsubsection{Scenario 2}

This scenario assesses the future aspects of the increase in electricity generation from wind sources, with particular reference to those connected to high voltage at $220 \mathrm{kV}$ at the "Sambuca" and "Cattolica Eraclea" stations. It is therefore assumed that the power generated by these two units increases up to $150 \%$ of the current nominal power, Table 1 . In Figure 4, the same power flows as outlined for the previous scenarios are reported. It is evident that the large amount of power now injected by wind farms ( $800 \mathrm{MW}$ ) contributes, for the most part, to the power flowing through the new Sicily-Malta connecting cable. To find out more about this aspect, refer to the next paragraph on tracing power flows.

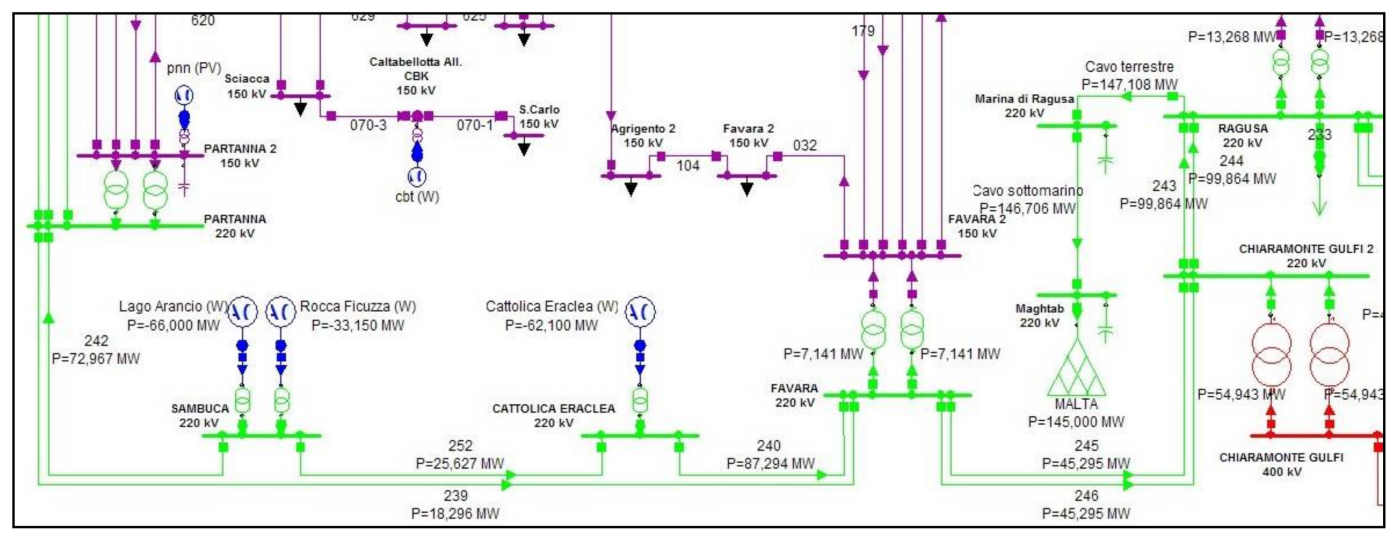

Figure 4. Scenario 2-Power flows on the portion of the network near the submarine interconnection connected to Ragusa station. 


\subsubsection{Power Flow Tracing Technique}

Power flow tracing methods allow the system operator to evaluate the contribution of the generation groups to the power flows on the electrical lines and the contribution of each user. In this study, thanks to this tracing technique, considering the export of energy to Malta as a simple load, it is possible to evaluate the contribution of the wind farms connected to the "Sambuca" and "Cattolica Eraclea" stations. As in [12], the node tracing method was performed, implementing the tracking algorithm using specially developed MATLAB ${ }^{\circledR}$ scripts. The system status was derived from the load flow evaluation performed using the NEPLAN ${ }^{\circledR}$ tools. Table 2 shows the results obtained following the simulation of scenario 1; in particular, the contribution of wind farms cited above is reported, which is equal to just under $20 \%$ of the export of electrical power on the submarine cable, which is $145 \mathrm{MW}$. In scenario 2, the production of electrical power by these units is greatly increased, and the results are reported in Table 2 . In this case the contribution of wind farms grew to $35 \%$ of the total export to the Maltese territory.

Table 2. Wind farms contributions to power export Sicily to Malta.

\begin{tabular}{lcc}
\hline Data & $\mathbf{P}_{\text {Malta }}$ (MW) Scenario 1 & $\mathbf{P}_{\text {Malta }}$ (MW) Scenario 2 \\
\hline Sambuca & 11,463 & 21,493 \\
Cattolica Eraclea & 15,927 & 29,862 \\
Total & 27,390 & 51,356 \\
Percentage with respect to total power export & $18,889 \%$ & $35,418 \%$ \\
\hline
\end{tabular}

The results obtained so far, thanks to the use of the flow tracing method, allow us to affirm that the new Italy-Malta connection allows a better exploitation of the wind plants installed in the Sicilian territory.

\subsection{Connected Configuration}

The second configuration (Malta and Sicily connected to the European grid) is, of course, more favorable. In this case authors report one year real operational data and then discuss the results and the benefits for the system. The Figure 5 shows the trend of the active power and the Figure 6 the percentile values of the active power exchanged with the Maltese electricity system, both figures refer to the period January 2017-January 2018.

More generally, it can be noted that, since its installation, on several occasions the transit on the Sicily-Malta international connection has been close to the nominal flow rate of the cable itself, and this was due to reasons related to the economic efficiency of supplying resources but also the unavailability of some Maltese generation groups. These groups have been the subject of repowering and have forced the Maltese electricity system operator to supply the production resources lost from abroad, that is, from the Sicilian electrical system, exploiting the interconnection cable. Certainly it can be said that the Sicily-Malta $220 \mathrm{kV}$ interconnection cable has played an important role, as it has powered and sustained the Maltese electrical system, ensuring stability in terms of stability of frequency and voltage on the $132 \mathrm{kV}$ distribution Maltese system and representing a hot reserve to the loss of generation inside the island and a reserve in supplying the demand curve during the unavailability of some generation group. It should also be emphasized that the high exploitation of this interconnection compared to the power requirement of the Maltese electrical system has been, on certain occasions, a contributing factor to the various blackouts to which the Maltese electrical system has been subjected. During these accidental interruptions of the power supply through the interconnection cable, the high ratio of power in import compared to the Maltese island demand, exposed the same Maltese Island to non-manageable under frequency transients in terms of primary regulation of the groups and not manageable even by the contribution given by the automatic load balancers, predisposed for the control of the frequency degradation, causing precisely the blackout of 
the Island. Despite this, the Maltese electrical system was able to react, as it is equipped with internal generation resources, which were promptly activated to re-start the island and allow the connection with the continental electricity system and restore normal operating conditions. Another important consideration on the operation refers to the doubling of the $400 \mathrm{kV}$ interconnection between the Sicilian and Italian continental electric systems. In fact the probability of operating in the island of simultaneous frequency of the two Islands (Sicily and Malta-islanded configuration) has been drastically reduced and this reduces the application of the operating restriction on the Sicily-Malta connection, which prevented a withdrawal above $150 \mathrm{MW}$ (as previously simulated) by the Maltese system operator. In Sicily, the doubling of $400 \mathrm{kV}$ interconnection with the mainland has changed the operation of power transits between Sicily and the Italian peninsula. When only one $400 \mathrm{kV}$ connection was operating, the Sicilian electrical system always exported energy to the continental one. This condition was essential for the safety of the Sicilian electricity system. The doubling of the interconnection has overturned this operating condition, in fact, due to market conditions, the production of conventional Sicilian power plants has been reduced, with the consequence that the Sicily now always imports energy from the Italian peninsula. In this new scenario great attention is paid by Terna to the voltage regulation on the nodes of the transmission network of the Sicilian electrical system. An important contribution is given by the two synchronous compensators installed in Sicily and by the power transferred in the Sicily-Malta $220 \mathrm{kV}$ interconnection cable, which in fact constitutes a load taken directly from the transmission network. Regarding the production from renewable sources, the limitations of wind production are in certain circumstances still present in Sicily but are no longer linked mainly to operational problems and structural deficiencies within the Sicilian electrical grid, which in recent years has been strengthened and it is discharged from the transport of important power flows thanks to the presence of distributed generation installed on the MV (PV) network. In order to promote maximum exploitation of renewable sources and to ensure an increase in the safety margins for the operation of the system, Terna identified one of the possible solutions to the problem in the storage of energy, and has therefore planned the installation of new storage technologies connected to the National Electricity Transmission Grid $[13,14]$. Under certain circumstances the limitations on renewable generation in HV (wind) remain due to the needs of the primary peninsular network. In particular, the limitations are linked to the relationship between production from renewable sources compared to the total power required by the Italian system, a parameter that must not exceed certain safety values. In this context, the island of Malta, when configured as a load, continues to represent an opportunity for the Sicilian electricity system and for renewable sources, which find space to be allocated in the supplying of energy needs. The authors also analyzed the statistics elaborated by GME (Italian Energy Market Operator) on the results of the electricity market from the year 2011 to 2016 (the 2017 report is not yet available) [15], with particular reference to the zonal price of Sicily and the HHI index (Herfindahl-Hirschman Index) always related to the Sicily area. HHI is an aggregate market index measuring the degree of concentration and dispersion of Volumes offered and/or sold by Market Participants. The HHI is calculated, for each hour and each Macro-Zone, as the sum of the shares of the Volumes sold (or offered) in the market by Market Participants, multiplied by 100 and squared. The value of the HHI may range from 0 (perfect competition) to 10,000 points (monopoly). The HHI is computed on an hourly basis and then aggregated into monthly simple averages. Figure 7 shows the trend of the zonal price of electricity in Sicily, while Figure 8 shows the trend of the HHI index. It is possible to see how, in the years 2014-2016, when the connection with Malta and the doubling of the Sicily-Italy connection came into operation, the zonal price of Sicily decreased significantly from $95 € /$ MWh to a price of about half $47 € /$ MWh recorded in 2016. The Herfindahl-Hirschman Index (HHI) index, which characterizes the competitiveness of a market, also recorded a significant decrease (halving its value) thus demonstrating greater flexibility of the system. 


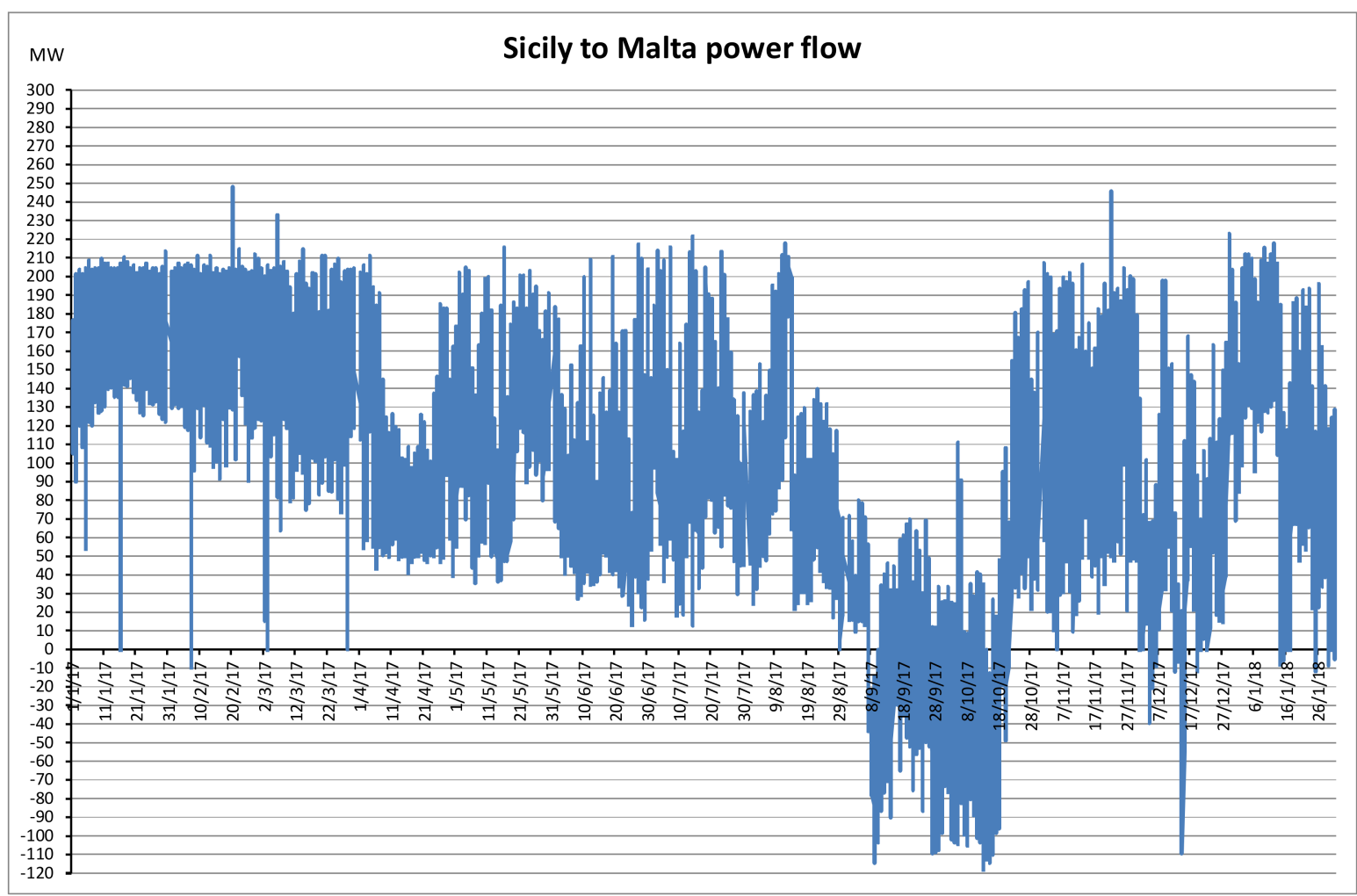

Figure 5. Sicily to Malta power flow from January 2017 to January 2018.

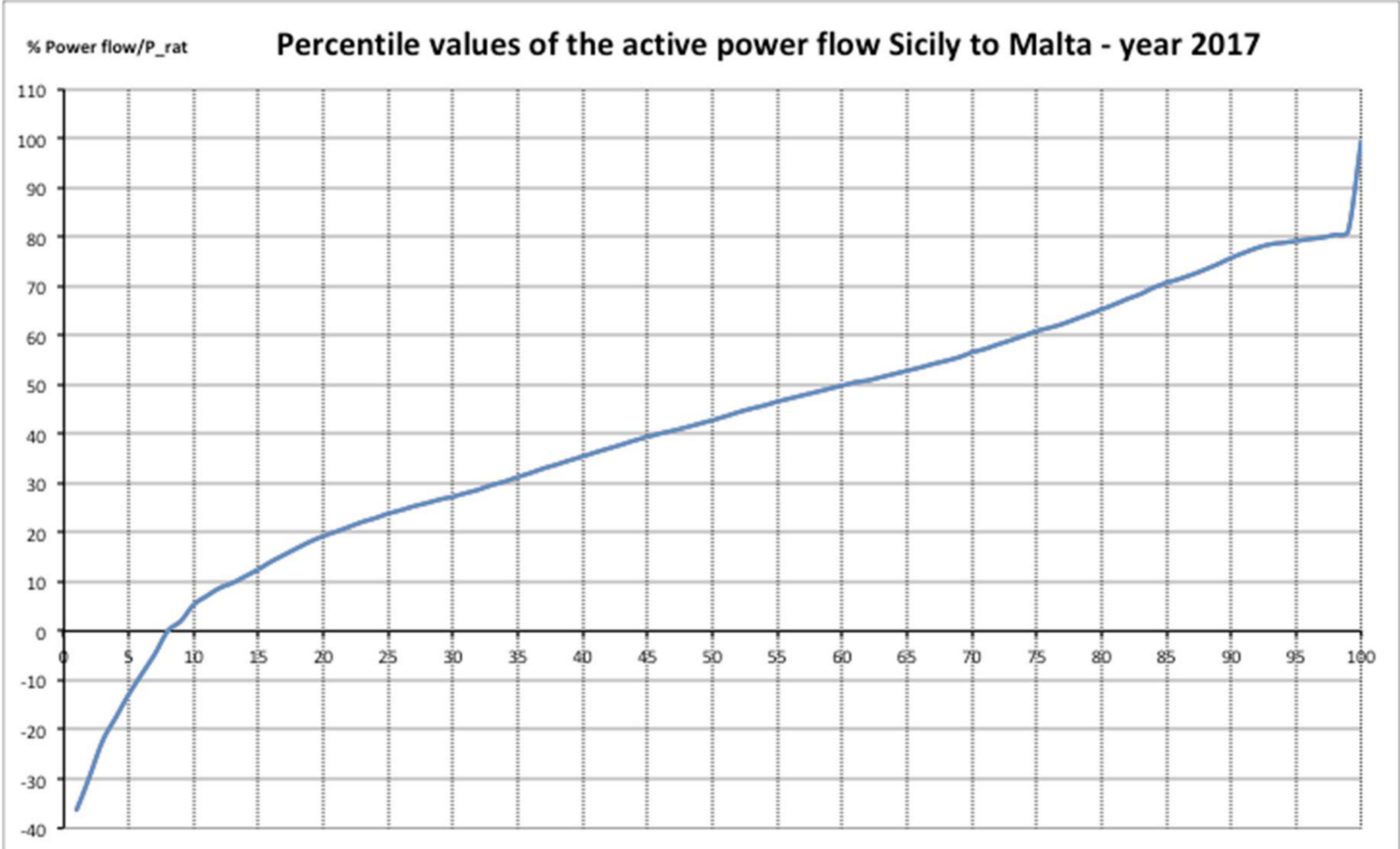

Figure 6. Percentile values Sicily to Malta power flow from January 2017 to January 2018. 


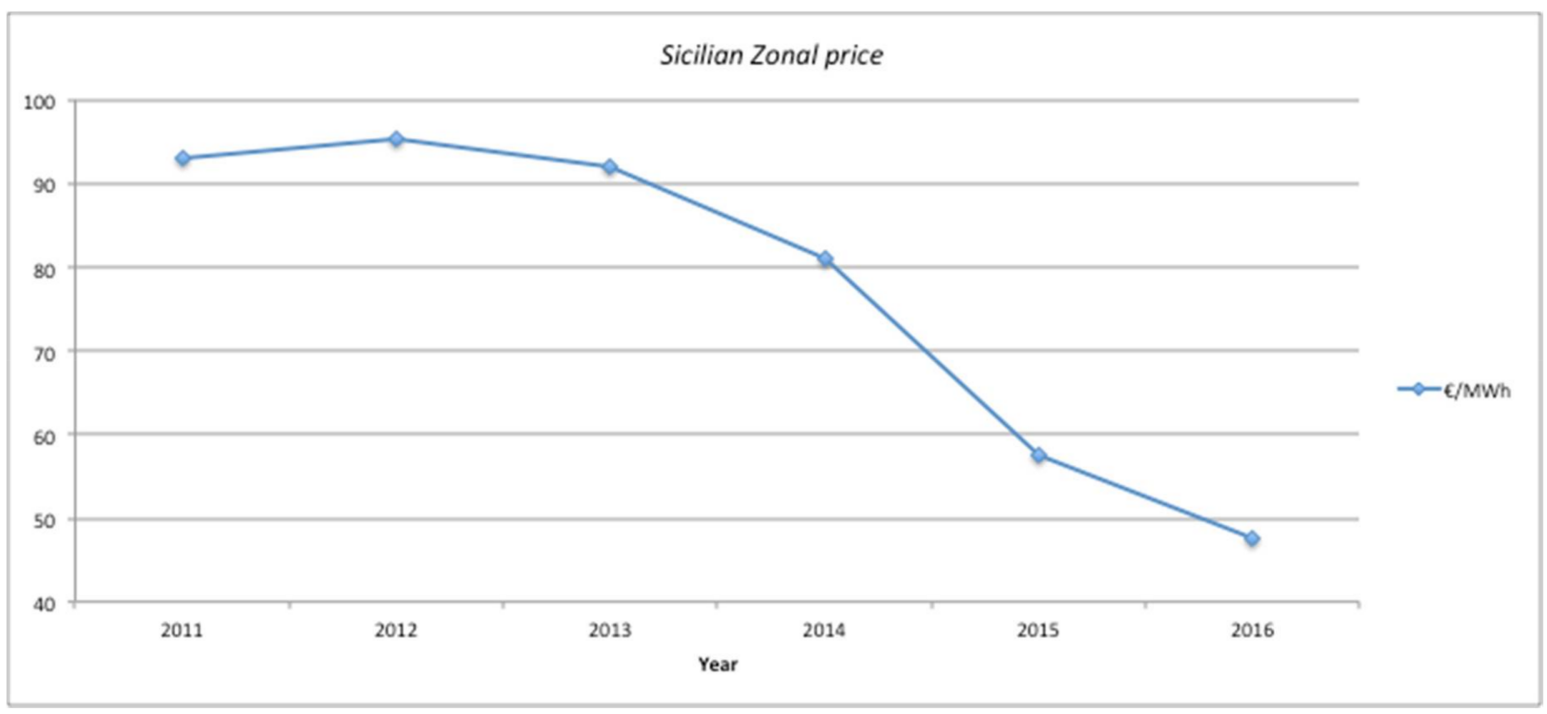

Figure 7. Sicilian electricity (zonal) price (period 2011-2016).

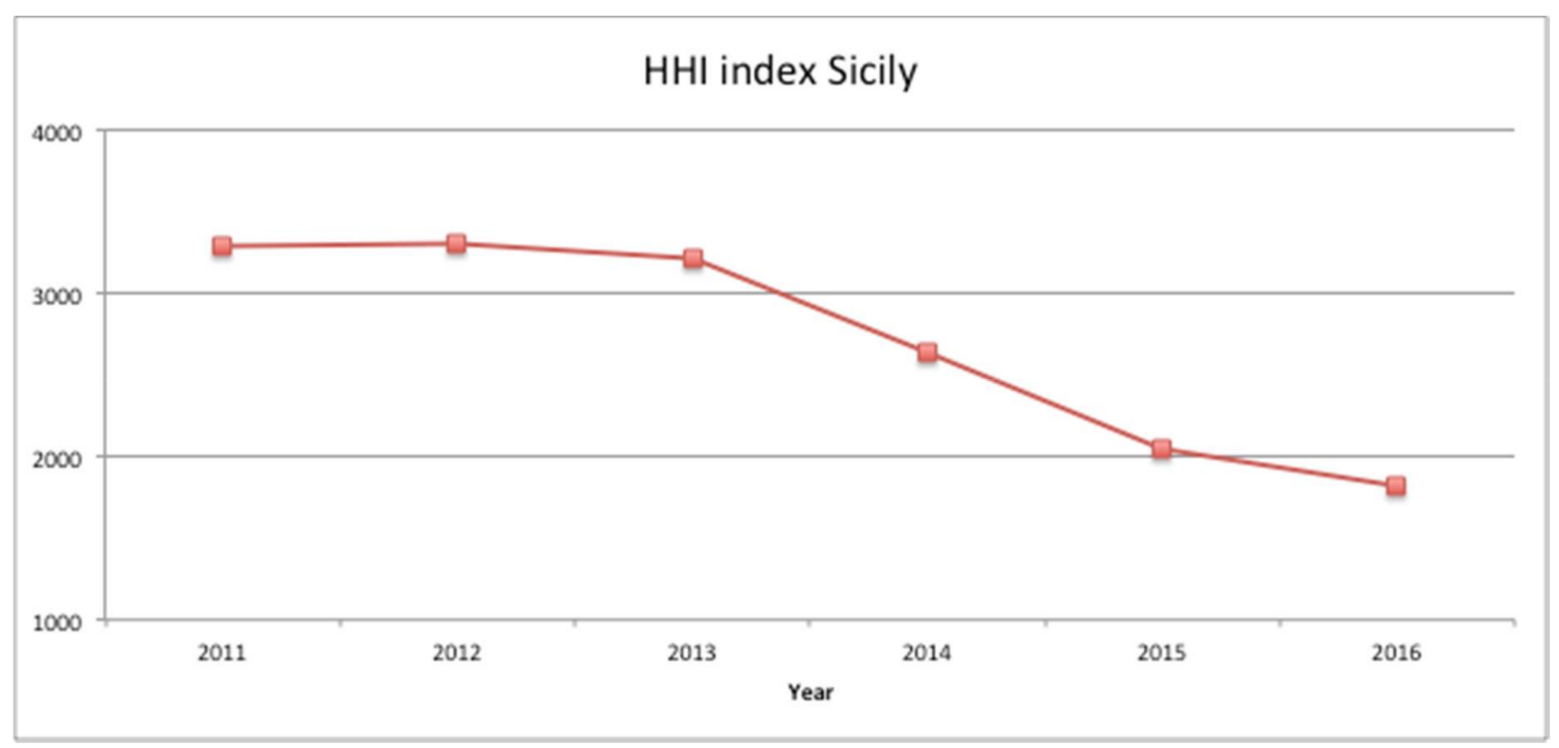

Figure 8. Sicilian HHI value (period 2011-2016).

\section{Results Discussion}

The main expected result is to improve the exploitation of wind farms, verifying the ways in which they can influence the export of electricity between Sicily and the island of Malta. It should be remembered that, among the initial hypotheses of condition 1, the islanded operation of the system was also considered and this is certainly a very conservative hypothesis with respect to reality. In the case of synchronous operation with the European network, the system acquires greater robustness, and it is possible to increase the production value from renewable sources; this allows, on the one hand, a better exploitation of RES, and on the other a mitigation of cost of the electricity for the island of Malta and for Sicily. Sicily has a significant presence of wind farms which, in good wind conditions, cover a good part of the electricity demand in Sicily. In case of isolated operation, the TSO, having to guarantee adequate safety margins, is forced to reduce the generation from RES and increase that from traditional power units. The new connection with the island of Malta allows, even in case of isolated operation, a better exploitation of the Sicilian wind farms with obvious benefits also on the final price of energy. Certainly it is also necessary to highlight some possible 
disadvantages related to this new interconnection. In fact, only in the case of operation isolated from the European system (the authors remember an absolutely remote hypothesis thanks to the doubling of the connection between Sicily and mainland Italy) the Sicilian transmission system is subject to many other disturbances because the regulation energy of the system decreases moderately. Furthermore, interruptions in the interconnection circuit could lead to severe under-frequency transients for the Maltese network. During island operation, problems related to frequency transients can occur even more frequently and severely, since the primary regulation energy of the Sicilian and Maltese power grid is much lower than the European grid. The procedures that regulate the operation of the new connecting cable provide emergency measures to limit any negative effects of these results. Therefore in the scenarios assuming condition 1 Sicily produces a greater quantity of power compared to its electricity demand ensuring a good export of power to the island of Malta. The traditional Maltese power stations, on the other hand, guarantee the residual electricity demand of the island. Lastly, it should be noted that the unplanned interruptions of the new interconnection cause an important disturbance for the Maltese system, causing a transient under frequency that could affect the stability of the power supply system itself or, at the limit, load-shedding.

\section{Conclusions}

This paper presents the new submarine links connecting Sicily, Malta and Italy (doubling), carrying out some simulations on the new network system configurations in condition 1 , and reports one year real operational data in condition 2 . The submarine cable, operated in alternating current, is among the longest in the world, with an extension of about $119 \mathrm{~km}$. Its implementation was funded by the EU under the European Energy Recovery Program (EEPR). The studies presented in this document demonstrate how these new links improve the exploitation of the power generated by RES. Three reference scenarios in islanded configuration have been hypothesized, in which the power injected by the wind farms connected to the HV system is progressively increased. The numerical evaluations, carried out by NEPLAN ${ }^{\circledR}$ load flow tool on a specially developed network model, show the fundamental contribution of RES production both to the coverage of Sicilian electric demand and to the power exported to the new connecting cable. The implementation of an electrical tracing method, developed in the MATLAB $^{\circledR}$ (Version 9.2, MathWorks, Natick, MA, USA) environment, shows that the wind farms connected to the $220 \mathrm{kV}$ grid, which are electrically close to the end of the Sicilian submarine interconnection, are responsible for a very considerable percentage of the power exported to Malta. The presence of the double connection Sicily-Italy has allowed also a decrease in the zonal price of electricity in Sicily and a greater flexibility of the electricity market, attested by a significant decrease in the HHI index.

Author Contributions: Mariano Giuseppe Ippolito and Fabio Massaro proposed the core idea and developed the model, performed simulations and analyzed the results, Salvatore Favuzza and Liliana Mineo analyzed the results and helped to write the document, Calogero Cassaro give the contribution of data from the Italian TSO.

Conflicts of Interest: The authors declare no conflict of interest.

\section{References}

1. Biondi, S.; Carlini, E.M.; Delfanti, M.; Vergine, C.; Quaciari, C. Possible development of national transmission network in Sicily in order to maximise wind energy dispatch. L'Energia Elettrica 2011, 88, 9-20.

2. Favuzza, S.; Ippolito, M.G.; Massaro, F.; Paternò, G.; Puccio, A. 2015-2020. Sicily and Italy as Electricity $\mathrm{Hub}$ in the Mediterranean Area for the Development of the European Power Grids Interconnections. In Proceedings of the IEEE 5th International Conference on Power Engineering, Energy and Electrical Drives (POWERENG 2015), Riga, Latvia, 11-13 May 2015; pp. 554-559.

3. Colla, L.; Marelli, M.; Lauria, S.; Schembari, M.; Palone, F.; Rebolini, M. Mediterranean high voltage submarine cable links technology and system challenges. In Proceedings of the 2013 AEIT Annual Conference, Mondello, Italy, 3-5 October 2013. 
4. Ohki, Y.; Yasufuku, S. The world's first long distance 500 kV-XLPE cable line. 3. Underground Apparatus. IEEE Electr. Insul. Mag. 2002, 18, 44-45. [CrossRef]

5. Rahman, N. 220 kV Long Distance Underground HVAC Cable Circuit. In Proceedings of the AORC Technical Meeting, CIGRÉ, Tokyo, Japan, 27-29 May 2014.

6. Cigré. Implementation of long AC HV and EHV cable systems. In Cigré Technical Brochure n. 680; Cigré: Paris, France, 2017.

7. European Energy Programme for Recovery. Available online: http:/ /ec.europa.eu/energy/eepr/projects/ (accessed on 11 January 2016).

8. European Commisison. Limiting Global Climate Change to 2 Degrees Celsius-The Way ahead for 2020 and Beyond; European Commisison: Brussels, Belgium, 2007.

9. Caciolli, L.; Carlini, E.M.; Cassaro, C.; Giannuzzi, G.M.; Pascucci, A.; Favuzza, S.; Ippolito, M.G.; Madonia, A.; Massaro, F.; Paternò, G. Sicily-Malta: The new AC 220 kV national transmission network interconnection. L'Energia Elettrica. 2015, 92, 19-29.

10. Enemalta, the Network Code, Approved by the Malta Resources Authority, October 2013. Available online: http:/ / enemalta.com.mt/EnemaltaStorage//Images/Files/Network\%20Code/Network\% 20Code\%20EMC\%20Approved\%20\%20October\%202013.pdf (accessed on 11 January 2016).

11. Paterno, G.; Madonia, A.; Ippolito, M.G.; Massaro, F.; Favuzza, S.; Cassaro, C. Analysis of the New Submarine Interconnection System between Italy and Malta: Simulation of Transmission Network Operation. In Proceedings of the 16th International Conference on Environment and Electrical Engineering (EEEIC 2016), Florence, Italy, 7-10 June 2016.

12. Dusonchet, L.; Favuzza, S.; Ippolito, M.G.; Massaro, F.; Paternò, G. Numerical Implementation of Active Power Flow Tracing Methods: Practical Implications on Transmission Networks and DR Programs Support. In Proceedings of the IEEE 15th International Conference on Environment and Electrical Engineering (EEEIC 2015), Rome, Italy, 10-13 June 2015; pp. 531-536.

13. Andriollo, M.; Benato, R.; Sessa, S.D.; di Pietro, N.; Hiray, N.; Nakanishi, Y.; Senatore, E. Energy intensive electrochemical storage in Italy: 34.8 MW sodium-sulphur secondary cells. J. Energy Storage 2016, 5, 146-155. [CrossRef]

14. Gatta, F.M.; Geri, A.; Lauria, S.; Maccioni, M.; Codino, A.; Gemelli, G.; Palone, F.; Rebolini, M. Modelling of Battery Energy Storage Systems under Faulted Conditions: Assessment of Protection Systems Behavior. In Proceedings of the IEEE 16th International Conference on Environment and Electrical Engineering (EEEIC), Florence, Italy, 7-10 June 2016.

15. Gestore Mercati Energetici. Available online: http://www.mercatoelettrico.org/It/Default.aspx (accessed on 7 March 2018).

(C) 2018 by the authors. Licensee MDPI, Basel, Switzerland. This article is an open access article distributed under the terms and conditions of the Creative Commons Attribution (CC BY) license (http://creativecommons.org/licenses/by/4.0/). 